\title{
The Importance of Testing Multiple Environmental Factors in Legume-Insect Research: Replication, Reviewers, and Rebuttal
}

\author{
Scott N. Johnson*, Andrew N. Gherlenda, Adam Frew and James M. W. Ryalls \\ Hawkesbury Institute for the Environment, Western Sydney University, Penrith, NSW, Australia
}

Keywords: atmospheric change, biological nitrogen fixation, climate change, insect-plant interactions, legumes, pastures

\section{THE CASE FOR TESTING MULTIPLE ENVIRONMENTAL FACTORS}

Investigating the impacts of predicted changes in our atmosphere and climate change on insectplant interactions is a widely pursued area of research. To date, the majority of experimental studies have tested the impacts of single environmental factors on insect-plant interactions, but meta-analyses have clearly illustrated the importance of investigating multiple factors in tandem (Zvereva and Kozlov, 2006; Robinson et al., 2012). In particular, environmental change factors often interact with each other which can either strengthen or mitigate the effects of

OPEN ACCESS

Edited by:

Michael Rostás,

Lincoln University, New Zealand

Reviewed by:

Federico Tomasetto,

AgResearch Ltd., New Zealand

*Correspondence:

Scott N. Johnson

scott.johnson@westernsydney.edu.au

Specialty section:

This article was submitted to Agroecology and Land Use Systems, a section of the journal

Frontiers in Plant Science

Received: 15 March 2016 Accepted: 26 March 2016

Published: 22 April 2016

Citation:

Johnson SN, Gherlenda AN, Frew A and Ryalls JMW (2016) The

Importance of Testing Multiple

Environmental Factors in

Legume-Insect Research: Replication,

Reviewers, and Rebuttal.

Front. Plant Sci. 7:489.

doi: 10.3389/fpls.2016.00489 environmental factors acting alone (Robinson et al., 2012). For example, the positive effects of elevated atmospheric carbon dioxide concentrations $\left(e\left[\mathrm{CO}_{2}\right]\right)$ on plant growth are stronger under high nitrogen $(\mathrm{N})$ conditions compared to low $\mathrm{N}$ conditions ( +32 and $+19 \%$, respectively; Robinson et al., 2012). Likewise, from the limited number of studies available, Robinson et al. (2012) showed that $\mathrm{e}\left[\mathrm{CO}_{2}\right]$ had different impacts on plant nitrogen, plant biomass, and secondary metabolites under elevated air temperature (eT) conditions. This does not invalidate single factor studies, of which we have published numerous examples, but this is an important consideration for making realistic predictions about how plants and insects will respond to future climates (Facey et al., 2014).

\section{LEGUME-INSECT INTERACTIONS}

A key feature of legumes is their capacity for biological nitrogen fixation (BNF), which they accomplish via symbiotic relationships with soil bacteria which associate with the plant in discrete root nodules. Given that insect herbivores are frequently nitrogen limited (Mattson, 1980), concentrations of $\mathrm{N}$ in legumes derived from $\mathrm{BNF}$ are likely to be crucial determinants of plantherbivore interactions. Legumes differ markedly from non-legume plants in their responses to environmental change because BNF is often significantly affected (Robinson et al., 2012). Moreover, $\mathrm{e}\left[\mathrm{CO}_{2}\right]$ and eT appear to have contrasting effects on BNF; $\left[\mathrm{CO}_{2}\right]$ tends to promote BNF via several mechanisms (Soussana and Hartwig, 1996), including larger numbers of $\mathrm{N}_{2}$-fixing symbiotic bacteria in the rhizosphere (Schortemeyer et al., 1996), increased nodulation (Ryle and Powell, 1992) and enhanced nitrogenase activity (Norby, 1987). In contrast, eT tends to have an inhibitory effect on BNF because of the low tolerance of $\mathrm{N}_{2}$-fixing bacteria to higher temperatures (Zahran, 1999; Whittington et al., 2013). These generalizations are, of course, contingent on nutrient availability in the soil (e.g., Edwards et al., 2006).

Given this, one might assume that $\mathrm{e}\left[\mathrm{CO}_{2}\right]$ and $\mathrm{eT}$ might have contrasting impacts on insect herbivores of legumes since they affect nitrogen concentrations in the plant 
tissues in a divergent manner. This seems to be the case, with $\mathrm{e}\left[\mathrm{CO}_{2}\right]$ either having no adverse effects (e.g., Karowe and Migliaccio, 2011) or, more often, a beneficial impact on herbivore performance (e.g., Johnson and McNicol, 2010), particularly for aphids (Guo et al., 2013, 2014; Johnson et al., 2014). However, our recent work with lucerne (Medicago sativa) has shown that the positive impacts of $\mathrm{e}\left[\mathrm{CO}_{2}\right]$ on pea aphids (Acyrthosiphon pisum) were negated under eT because eT caused decreases in nodulation and amino acid concentrations in the foliage (Ryalls et al., 2013, 2015). Testing multiple environmental factors, including soil nutrients, therefore seems to be particularly relevant for investigations into how legume herbivores will respond to atmospheric and climate change research.

\section{THE CHALLENGES: REPLICATION AND REVIEWERS}

Why are there so few multi-factorial experiments in climate change research? Put simply, constraints on replication are the biggest obstacles faced by investigators. Pseudoreplication (a term first coined in Hurlbert, 1984) is particularly common in climate change research (Newman et al., 2011). For example, 49 of the 110 climate change studies reviewed by Wernberg et al. (2012) had pseudoreplication issues. This usually arises because when environmental factors are applied to controlled chambers, glasshouses, or FACE (Free Air $\mathrm{CO}_{2}$ Enrichment) rings, the unit of replication for those treatments is the chamber, greenhouse, or ring, respectively (Lindroth and Raffa, in press). Subunits (e.g., individual plants) are not independently subjected to the treatment, and therefore not true replicates. As a result, statistical tests are based on artificially high degrees of freedom, resulting in a larger $\mathrm{F}$ statistic, potentially leading to type I errors (i.e., false positives; Lindroth and Raffa, in press). For this reason, many reviewers for scientific journals automatically reject manuscripts if any part of an experiment is pseudoreplicated without necessarily considering whether the biological conclusions of the study are really compromised by pseudoreplication (Davies and Gray, 2015). This is possibly an overzealous interpretation of the case by Hurlbert (1984), the authority on the subject, who states that "there should be no automatic rejection of [such] experiments" (Hurlbert, 2004). In a recent and comprehensive article, Davies and Gray argue convincingly that reviewers erroneously and dogmatically reject papers that have pseudoreplication issues which is slowing the pace of ecological research. While Davies and Gray (2015) focussed on non-manipulative experiments in natural systems, many of the points were germane to multi-factorial climate change research. In particular, many contemporary statistical tests, such as nested designs and random/mixed effect models, account for the lack of independence between pseudoreplicates so may help in some cases (Chaves, 2010; Leather et al., 2014; Davies and Gray, 2015). Of course, such statistical approaches could only help where a treatment combination was repeated in more than one chamber, glasshouse, or FACE ring.

\section{COMPARING EXPERIMENTAL APPROACHES-POTENTIAL FOR REBUTTAL?}

How do researchers attempt to overcome the pseudoreplication problem experimentally? The simplest way is to avoid it altogether by fully replicating environmental treatments. However, using even the bare minimum of replicates (e.g., $N=4$ ) would require 16 separate chambers, glasshouses, or rings for an $\mathrm{e}\left[\mathrm{CO}_{2}\right] \times \mathrm{eT}$ experiment. Many researchers cannot readily access this number of identical facilities or monopolize them for that matter. Repeating the experiment several times and using experimental run as the source of replication is another approach (e.g., Johnson et al., 2011), but this can be logistically demanding in time and cost. Even when fully replicated, the degrees of freedom in these studies are often so low that they are susceptible to type II errors, whereby "real responses" are not statistically detected (e.g., the "false negative").

Another approach that researchers sometimes use is "chamber swapping", whereby experimental units (e.g., plants) are moved within, and then between, chambers with attendant changes in environmental conditions (e.g., Bezemer et al., 1998). This does not eliminate pseudoreplication, but rather serves to minimize its effects by equalizing any unintended "chamber effects" across all experimental units. While this approach might be criticized because chamber effects might affect plants differently during different stages of their development (Potvin and Tardif, 1988), researchers have addressed this by staggering experiments so plants are exposed to particular chambers at the same stage of development (e.g., Vuorinen et al., 2004a,b).

How do results from a "chamber swapping" experiment compare with replicated experiments? We can answer this question, in part, using three comparable published studies that examined the impacts of environmental change on interactions between lucerne and the pea aphid. One experiment was replicated using multiple chambers (Johnson et al., 2014), one replicated using multiple experimental runs (Ryalls et al., 2015) and one adopted the chamber swapping approach (Ryalls, 2016). The first of these only examined $\mathrm{e}\left[\mathrm{CO}_{2}\right]$, whereas the other two experiments also included eT. Figure 1 shows the increase in dry mass of plants (with and without aphids) grown under $\mathrm{e}\left[\mathrm{CO}_{2}\right]$ and eT relative to plants grown under ambient conditions. This response was selected for comparison since it was evidently measured the same way in each experiment. Despite using very different approaches, in most cases we obtained very similar responses whether the experiment was fully replicated or conducted with regular chamber swaps (c. every 10 days). Analysis of variance suggested that study type had little impact on the response we measured $\left[F_{(2,219)}=0.20, P=0.82\right]$. This is a crude 


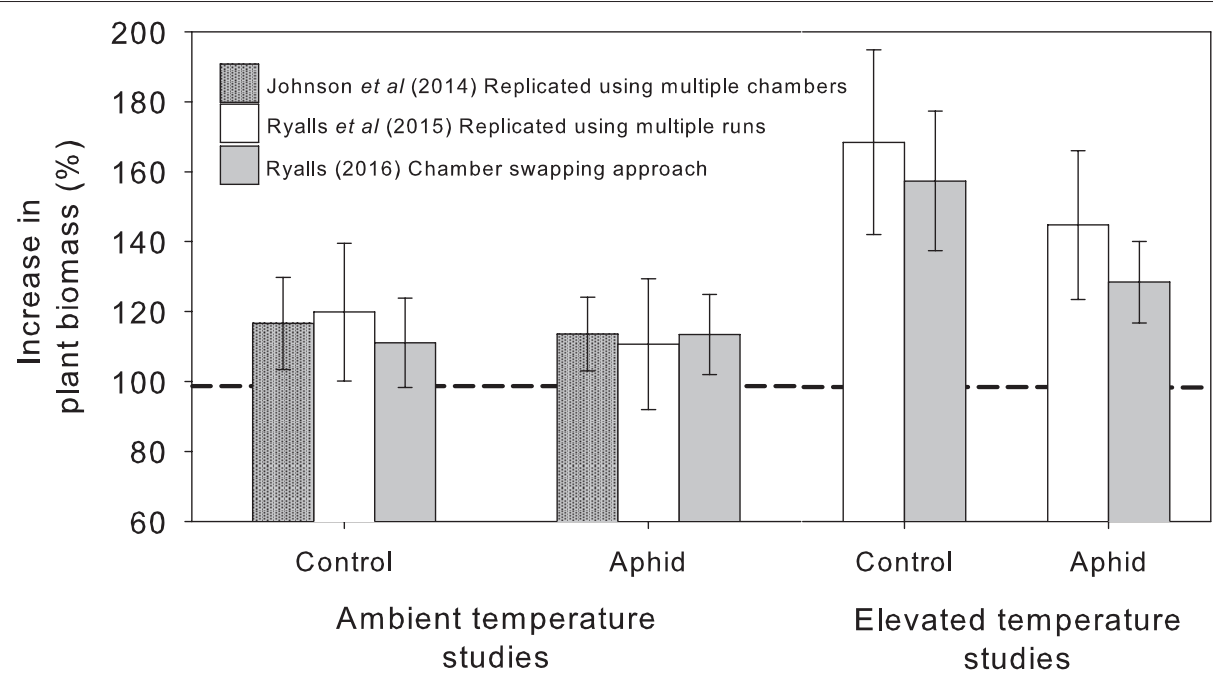

FIGURE 1 | Relative change in plant biomass at elevated $\left[\mathrm{CO}_{2}\right]$ compared to plants grown at ambient $\left[\mathrm{CO}_{2}\right]$, indicated with the dashed line, with and without (control) aphids (mean \pm S.E. shown). Data from three experiments using replication with multiple chambers (Johnson et al., 2014) and multiple experimental runs (Ryalls et al., 2015) compared with the "chamber swapping" approach (Ryalls, 2016). All experiments used the same cultivar (Sequel) and similar levels of $\left[\mathrm{CO}_{2}\right]$ (400 vs. 600-640 ppm) and temperature (25-26 vs. $30^{\circ} \mathrm{C}$ ).

comparison, but it is reassuring that we obtained similar data and reached identical conclusions using the chamber swapping approach.

\section{CONCLUSIONS AND RECOMMENDATIONS}

While incorporation of multiple environmental factors is desirable in many climate change studies of plant-herbivore interactions (clearly advocated by Robinson et al., 2012), we argue here that it is especially relevant to legume-insect research. Nitrogen status in legumes is shaped by BNF, which is highly affected by atmospheric and climatic change, often in divergent directions. This will inevitably affect legume quality for herbivores (i.e., especially primary metabolites, but possibly secondary metabolites too), and likely affect herbivore abundance and performance. Nonetheless, experimental manipulation of multiple factors is challenging and prone to pseudoreplication. "Chamber swapping" does not eliminate this problem, but it appears to minimize "chamber effects" and give comparable results to fully replicated experiments-at least in the lucerneaphid system. We recommend that researchers working in other systems also take a cautious approach with regard to careful replication until they can develop confidence that their observed effects are real and repeatable. The statistical significance of

\section{REFERENCES}

Bezemer, T. M., Thompson, L. J., and Jones, T. H. (1998). Poa annua shows intergenerational differences in response to elevated $\mathrm{CO}_{2}$. Glob. Change Biol. 4, 687-691. doi: 10.1046/j.1365-2486.1998.00184.x numerical differences remain inflated, however, so it would be judicious to treat any marginally significant results with caution and rather interpret effect sizes rather than $P$-values per se (see discussion by Ellison et al., 2014). Davies and Gray (2015) make the similar arguments and suggest that conclusions can be phrased as new hypotheses if necessary. In conclusion, we agree with Newman et al. (2011) on this issue that "as long as authors are clear about the use of pseudoreplicates, and the readers appreciate the potential problems interpreting such results, then such studies are valuable despite their pseudoreplication."

\section{AUTHOR CONTRIBUTIONS}

SJ conceived and drafted the article with significant intellectual input from all authors. JR conducted the majority of the experimental work described in the article, with SJ, AG, and AF overseeing collection of further data used in Figure 1.

\section{ACKNOWLEDGMENTS}

The authors are grateful to Associate Professor Jeff Powell for helpful suggestions on this manuscript and students of the Invertebrate Biology unit (300918) at Western Sydney University for assistance collecting data. This opinion piece was published as part of a series of articles from the ninth Australasian Congress of Grassland Invertebrate Ecology.
Chaves, L. F. (2010). An entomologist guide to demystify pseudoreplication: data analysis of field studies with design constraints. J. Med. Entomol. 47, 291-298. doi: 10.1093/jmedent/47.1.291

Davies, G. M., and Gray, A. (2015). Don't let spurious accusations of pseudoreplication limit our ability to learn from natural experiments (and 
other messy kinds of ecological monitoring). Ecol. Evol. 5, 5295-5304. doi: $10.1002 /$ ece 3.1782

Edwards, E. J., McCaffery, S., and Evans, J. R. (2006). Phosphorus availability and elevated $\mathrm{CO}_{2}$ affect biological nitrogen fixation and nutrient fluxes in a clover-dominated sward. New Phytol. 169, 157-167. doi: 10.1111/j.14698137.2005.01568.x

Ellison, A. M., Gotelli, N. J., Inouye, B. D., and Strong, D. R. (2014). P values, hypothesis testing, and model selection: it's déjà vu all over again. Ecology 95, 609-610. doi: 10.1890/13-1911.1

Facey, S. L., Ellsworth, D. S., Staley, J. T., Wright, D. J., and Johnson, S. N. (2014). Upsetting the order: how climate and atmospheric change affects herbivoreenemy interactions. Curr. Opin. Insect Sci. 5, 66-74. doi: 10.1016/j.cois.2014. 09.015

Guo, H., Sun, Y. C., Li, Y., Liu, X., Zhang, W., and Ge, F. (2014). Elevated $\mathrm{CO}_{2}$ decreases the response of the ethylene signaling pathway in Medicago truncatula and increases the abundance of the pea aphid. New Phytol. 201, 279-291. doi: 10.1111/nph.12484

Guo, H., Sun, Y. C., Li, Y., Tong, B., Harris, M., Zhu-Salzman, K., et al. (2013). Pea aphid promotes amino acid metabolism both in Medicago truncatula and bacteriocytes to favor aphid population growth under elevated $\mathrm{CO}_{2}$. Glob. Change Biol. 19, 3210-3223. doi: 10.1111/gcb.12260

Hurlbert, S. H. (1984). Pseudoreplication and the design of ecological field experiments. Ecol. Monogr. 54, 187-211. doi: 10.2307/1942661

Hurlbert, S. H. (2004). On misinterpretations of pseudoreplication and related matters: a reply to Oksanen. Oikos 104, 591-597. doi: 10.1111/j.00301299.2004.12752.x

Johnson, S. N., Barton, A. T., Clark, K. E., Gregory, P. J., McMenemy, L. S., and Hancock, R. D. (2011). Elevated atmospheric carbon dioxide impairs the performance of root-feeding vine weevils by modifying root growth and secondary metabolites. Glob. Change Biol. 17, 688-695. doi: 10.1111/j.13652486.2010.02264.x

Johnson, S. N., and McNicol, J. W. (2010). Elevated $\mathrm{CO}_{2}$ and abovegroundbelowground herbivory by the clover root weevil. Oecologia 162, 209-216. doi: 10.1007/s00442-009-1428-4

Johnson, S. N., Ryalls, J. M. W., and Karley, A. J. (2014). Global climate change and crop resistance to aphids: contrasting responses of lucerne genotypes to elevated atmospheric carbon dioxide. Ann. Appl. Biol. 165, 62-72. doi: 10.1111/aab.12115

Karowe, D. N., and Migliaccio, A. (2011). Performance of the legume-feeding herbivore, Colias philodice (Lepidoptera: Pieridae) is not affected by elevated $\mathrm{CO}_{2}$. Arthropod Plant Interact. 5, 107-114. doi: 10.1007/s11829-010-9119-y

Leather, S. R., Basset, Y., and Didham, R. K. (2014). How to avoid the top ten pitfalls in insect conservation and diversity research and minimise your chances of manuscript rejection. Insect Conserv. Diver. 7, 1-3. doi: 10.1111/icad.12066

Lindroth, R. L., and Raffa, K. F. (in press). "Experimental approaches for assessing invertebrate responses to global change factors," in Invertebrates and Global Climate Change, eds S. N. Johnson and T. H. Jones (Oxford, UK: Wiley).

Mattson, W. J. Jr. (1980). Herbivory in relation to plant nitrogen content. Annu. Rev. Ecol. Syst. 11, 119-161. doi: 10.1146/annurev.es.11.110180.001003

Newman, J. A., Anand, M., Henry, H. A. L., Hunt, S., and Gedalof, Z. (2011). Climate Change Biology. Wallingford, UK: CABI.

Norby, R. J. (1987). Nodulation and nitrogenase activity in nitrogen-fixing woody plants stimulated by $\mathrm{CO}_{2}$ enrichment of the atmosphere. Physiol. Plantarum 71, 77-82. doi: 10.1111/j.1399-3054.1987.tb04620.x

Potvin, C., and Tardif, S. (1988). Sources of variability and experimental designs in growth chambers. Funct. Ecol. 2, 123-130. doi: 10.2307/2389472
Robinson, E. A., Ryan, G. D., and Newman, J. A. (2012). A meta-analytical review of the effects of elevated $\mathrm{CO}_{2}$ on plant-arthropod interactions highlights the importance of interacting environmental and biological variables. New Phytol. 194, 321-336. doi: 10.1111/j.1469-8137.2012.04074.x

Ryalls, J. M. W. (2016). The Impacts of Climate Change and Belowground Herbivory on Aphids via Primary Metabolites. Ph.D. thesis (Appendix IV).

Ryalls, J. M. W., Moore, B. D., Riegler, M., Gherlenda, A. N., and Johnson, S. N. (2015). Amino acid-mediated impacts of elevated carbon dioxide and simulated root herbivory on aphids are neutralised by increased air temperatures. J. Exp. Bot. 66, 613-623. doi: 10.1093/jxb/eru439

Ryalls, J. M. W., Riegler, M., Moore, B. D., Lopaticki, G., and Johnson, S. N. (2013). Effects of elevated temperature and $\mathrm{CO}_{2}$ on aboveground-belowground systems: a case study with plants, their mutualistic bacteria and root/shoot herbivores. Front. Plant Sci. 4:445. doi: 10.3389/fpls.2013.00445

Ryle, G. J. A., and Powell, C. E. (1992). The influence of elevated $\mathrm{CO}_{2}$ and temperature on biomass production of continuously defoliated white clover. Plant Cell Environ. 15, 593-599. doi: 10.1111/j.1365-3040.1992.tb01493.x

Schortemeyer, M., Hartwig, U. A., Hendrey, G. R., and Sadowsky, M. J. (1996). Microbial community changes in the rhizospheres of white clover and perennial ryegrass exposed to Free Air Carbon dioxide Enrichment (FACE). Soil Biol. Biochem. 28, 1717-1724. doi: 10.1016/S0038-0717(96)00243-X

Soussana, J. F., and Hartwig, U. A. (1996). The effects of elevated $\mathrm{CO}_{2}$ on symbiotic $\mathrm{N}_{2}$ fixation: a link between the carbon and nitrogen cycles in grassland ecosystems. Plant Soil 187, 321-332. doi: 10.1007/BF00017097

Vuorinen, T., Nerg, A.-M., and Holopainen, J. K. (2004a). Ozone exposure triggers the emission of herbivore-induced plant volatiles, but does not disturb tritrophic signalling. Environ. Pollut. 131, 305-311. doi: 10.1016/j.envpol.2004.02.027

Vuorinen, T., Nerg, A.-M., Ibrahim, M. A., Reddy, G. V. P., and Holopainen, J. K. (2004b). Emission of Plutella xylostella-induced compounds from cabbages grown at elevated $\mathrm{CO}_{2}$ and orientation behavior of the natural enemies. Plant Physiol. 135, 1984-1992. doi: 10.1104/pp.104.047084

Wernberg, T., Smale, D. A., and Thomsen, M. S. (2012). A decade of climate change experiments on marine organisms: procedures, patterns and problems. Glob. Change Biol. 18, 1491-1498. doi: 10.1111/j.1365-2486.2012.02656.x

Whittington, H. R., Tilman, D., and Powers, J. S. (2013). Consequences of elevated temperatures on legume biomass and nitrogen cycling in a field warming and biodiversity experiment in a North American prairie. Func. Plant Biol. 40, 1147-1158. doi: 10.1071/FP12345

Zahran, H. H. (1999). Rhizobium-legume symbiosis and nitrogen fixation under severe conditions and in an arid climate. Microbiol. Mol. Biol R. 63, 968-989.

Zvereva, E. L., and Kozlov, M. V. (2006). Consequences of simultaneous elevation of carbon dioxide and temperature for plant-herbivore interactions: a metaanalysis. Glob. Change Biol. 12, 27-41. doi: 10.1111/j.1365-2486.2005.01086.x

Conflict of Interest Statement: The authors declare that the research was conducted in the absence of any commercial or financial relationships that could be construed as a potential conflict of interest.

Copyright (C) 2016 Johnson, Gherlenda, Frew and Ryalls. This is an open-access article distributed under the terms of the Creative Commons Attribution License (CC BY). The use, distribution or reproduction in other forums is permitted, provided the original author(s) or licensor are credited and that the original publication in this journal is cited, in accordance with accepted academic practice. No use, distribution or reproduction is permitted which does not comply with these terms. 